\title{
Impact of combining GRACE and GOCE gravity data on ocean circulation estimates
}

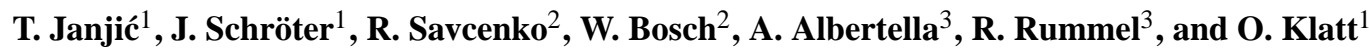 \\ ${ }^{1}$ Alfred Wegener Institute for Polar and Marine Research, Bussestrasse 24, 27570, Bremerhaven, Germany \\ ${ }^{2}$ Deutsches Geodätisches Forschungsinstitut, Munich, Germany \\ ${ }^{3}$ Institute for Astronomical and Physical Geodesy, TU Munich, Munich, Germany
}

Correspondence to: T. Janjić (tijana.janjic.pfander@awi.de)

Received: 22 May 2011 - Published in Ocean Sci. Discuss.: 27 June 2011

Revised: 12 January 2012 - Accepted: 23 January 2012 - Published: 8 February 2012

\begin{abstract}
With the focus on the Southern Ocean circulation, results of assimilation of multi-mission-altimeter data and the GRACE/GOCE gravity data into the finite element ocean model (FEOM) are investigated. We use the geodetic method to obtain the dynamical ocean topography (DOT). This method combines the multi-mission-altimeter sea surface height and the GRACE/GOCE gravity field. Using the profile approach, the spectral consistency of both fields is achieved by filtering the sea surface height and the geoid. By combining the GRACE and GOCE data, a considerably shorter filter length can be used, which results in more DOT details. We show that this increase in resolution of measured DOT carries onto the results of data assimilation for the surface data. By assimilating only absolute dynamical topography data using the ensemble Kalman filter, we were able to improve modeled fields. Results are closer to observations which were not used for assimilation and lie outside the area covered by altimetry in the Southern Ocean (e.g. temperature of surface drifters or deep temperatures in the Weddell Sea area at $800 \mathrm{~m}$ depth derived from Argo composite.)
\end{abstract}

\section{Introduction}

The vast majority of the observations of the global ocean come from satellite data. Altimetric measurements that measure the sea level height above the reference ellipsoid, are of high accuracy, have near global coverage, are continuous in time, and are available for almost $20 \mathrm{yr}$. In order to obtain absolute dynamical ocean topography (DOT) that represents the sea level height above the geoid, accurate information about the geoid height is needed. Previously, the geoid height estimates from the satellite only gravity field models were obtained with the data from the Gravity Recovery and Climate Experiment (GRACE) mission, and before that longer wavelength models were generated from laser and Doppler tracking of geodetic and other satellites. Recently, data from the Gravity field and steady-state Ocean Circulation Explorer (GOCE) satellite became available. Now, GOCE and GRACE satellite data can be combined to obtain a geoid with higher accuracy and spatial resolution (Pail et al., 2010). Although the altimetric sea surface that is needed for computation of DOT still resolves much shorter spatial scales than the geoid computed from the space gravity data, the increase in geoid accuracy and resolution also implies the higher resolution of DOT. Higher resolution spectrally filtered DOT, in addition to other oceanographic information available from in-situ and other space measurements, can be incorporated in general circulation models through data assimilation algorithms. This would allow us to predict changes in ocean circulation and to have more accurate estimates of less well observed ocean fields.

Incorporating DOT into a numerical ocean model through data assimilation is a difficult task because the ocean general circulation models commonly show systematic deviation from the measured mean dynamic topography. This systematic deviation can be caused by a variety of reasons including poor knowledge of surface forcing, inadequate parametrization of subgrid processes and missing details of the bottom topography used in the model. It is now a tradition in data assimilation algorithms to treat the mean DOT and its temporal variation separately (Penduff et al., 2002; Köhl et al., 2007; Stammer et al., 2007). The separation was introduced by Wenzel and Schröter (1995) for assimilating DOT into a 
ocean model, as an answer to the difference in accuracy between the highly accurate repeat altimetry data and the low accuracy geoid. Later, it became a common practice to subtract the average of sea surface height (SSH) from the measurements and to replace the average SSH by a separate estimate of the mean DOT from the ocean data or unconstrained ocean model. For example, the mean DOT can be obtained by first filtering the difference between the mean sea surface - obtained by gridding from along the track the mean altimetric profiles to regular grid - and the geoid. Such an estimate of the mean DOT is combined with drifting buoy velocities (Maximenko et al., 2009) as well as hydrological profiles (Rio et al., 2005, 2009). Also, the mean DOT can be obtained by synthesizing all oceanographic information through inverse modeling (Le Grand et al., 2003). In our study, the mean DOT and its variability are not separated. Instead, time series of 10 day "absolute" DOTs are generated using the satellite altimetry and our knowledge of the geoid (Skachko et al., 2008) as given by the GOCO1S model. Such a 10 day geodetic DOT time series is then assimilated into the ocean model for one year. The data assimilation method that we will use is ensemble Kalman filtering. The method is described in detail for assimilation of the geodetic DOT from the altimetry and the GRACE data in Janjić et al. (2011a,b). Our focus is on the Southern Ocean. We concentrate on the resolution of the DOT and study how different spatial filtering impacts ocean circulation estimates.

The first part of the paper will explain the procedure for obtaining the measured DOT as well as the differences in the information content due to the higher data resolution. In the second part of the paper we will examine the impact of the increased spectral content of the measured DOT on ocean fields as represented by a finite element ocean model. We will show how we are dealing with the increase in the spectral content of the measured DOT in the data assimilation algorithm. The increase in resolution carries onto the results of data assimilation for the surface variables. Finally, we will investigate our results in the Southern Ocean in more detail. By assimilating globally the DOT data, the ocean fields in Southern Ocean can be improved even in areas outside the coverage by altimetry. In particular, we will show that by assimilating only the absolute dynamical topography data using the ensemble Kalman filter, we are able to obtain improvements in the Weddell Sea area for temperature at $800 \mathrm{~m}$ depth. The Weddell Sea is neither well observed from satellites, nor using conventional observing platforms that are sparse and limited to specialized deep drifters and the CTD measurements mostly along hydrographic sections (Fahrbach, 1999; Fahrbach and Naggar, 2001; Fahrbach et al., 2003; Fahrbach and de Baar, 2010). On the other hand, the Weddell Sea area plays an important role due to the impact of circumpolar bottom water production on global deep sea circulation. The ability of numerical models together with data assimilation to better represent ocean fields in this area is therefore crucial for proper estimates of ocean circulation.

\section{Ocean model}

The ocean model used in this study is the Finite-Element Ocean circulation Model (FEOM) (Danilov et al., 2004; Wang et al., 2008). The model is configured on a global, almost regular triangular mesh with spatial resolution of $1.5^{\circ}$, and with 24 unevenly spaced levels in the vertical. The ocean model solves the standard set of hydrostatic ocean dynamics primitive equations. It uses a finite-element flux corrected transport algorithm for tracer advection (Löhner et al., 1987).

The model is forced at the surface with momentum fluxes derived from the ERS scatterometer wind stresses complemented by Tropical Atmosphere Ocean Array (TAO) derived stresses (Menkes et al., 1998). The vertical mixing is parameterized by Pakanowsky-Philander scheme (Pakanowski and Philander, 1981). The thermodynamic forcing is replaced by restoring of surface temperature and salinity to monthly mean surface climatology of WOA01 (Stephens et al., 2002). The model is initialized by mean climatological temperature and salinity of Gouretski and Koltermann (2004).

The FEOM ocean model has been tested in several previous studies. In a recent study, Sidorenko et al. (2011) compared the FEOM model to other ocean models participating in the experiment under the normalized year forcing of Coordinated Ocean-ice Reference Experiments. This showed that the ocean state simulated by FEOM is in most cases within the spread of other models. The FEOM model was also compared to the independent data and used for data assimilation studies with real observations in the work of Skachko et al. (2008); Rollenhagen et al. (2009); Janjić et al. (2011a,b). Further, Timmermann et al. (2009) examined the properties of the model with its standard setup and compared its transport estimates in the Southern Ocean with those from observations. Especially hydrographic properties were simulated fairly accurately, but more research needs to be done in this context on the role of eddies, the freshwater budget and the inflow from the east into the Weddell Gyre in order to better understand the rates of water mass production in the model (Schröder and Fahrbach, 1999).

\section{Data}

In this section, the procedure for obtaining the geodetic DOT data sets is explained. The DOT data sets of varying resolution are analyzed. In addition the data used for validation of results in the Weddell Sea and Southern Ocean is introduced.

\subsection{Geodetic dynamical ocean topography}

As already pointed out, the DOT can be constructed from geodetic data using an altimetric sea surface and an accurate geoid. This apparently simple concept has to be applied with care since spectral properties of sea surface height data and the geoid are different. The geoid is expressed spectrally by a spherical harmonic series, the sea surface height is generally 
available in gridded form and resolves shorter spatial scales than the geoid. Therefore, spectral consistency of these two surfaces must be ensured to avoid errors that otherwise may be introduced in the DOT (Schröter et al., 2002; Losch and Schröter, 2004; Bingham et al., 2008). Moreover, the gridded sea surface itself is already a derived product, generated by resampling the sea surface heights originally observed along the ground tracks of satellite altimetry. In this section a procedure for obtaining a time series with 10 day snapshots of DOT is explained and properties of the data set obtained are discussed.

The geodetic dynamic ocean topography is defined as the difference between sea surface heights $h$ and geoid heights $N$,

$\mathrm{DOT}=h-N$.

First, it has to be emphasized that the two quantities to be subtracted should be independent of each other. This implies that the geoid heights $N$ must be computed from gravity field models estimated without any surface gravity which is over ocean area obtained from altimetry itself. Satellite-only gravity fields, derived exclusively from GRACE or GOCE data satisfy, this condition and avoid the risk that geoid heights are corrupted by altimetry. Thus, for this study, geoid heights were computed from the ITG-Grace03s (Mayer-Gürr, 2007) and GOCO01S (Pail et al., 2010) gravity field models. Both quantities $h$ and $N$ are usually computed w.r.t. an ellipsoid of revolution. Naturally, the same ellipsoid has to be considered. In addition, the permanent tidal deformation which is due to the attraction of Sun and Moon has to be treated in the same way for both, the sea surface and the geoid. The sea surface heights $h$ were computed from the simultaneously operating altimeter missions ENVISAT, GFO, Jason-1 and TOPEX/Poseidon (on its interleaved ground track). The altimetric mission, data source and repeat cycle of each mission used for computing DOT are listed in Table 1. The different sampling characteristics of these missions ensure the best possible spatial coverage through the entirety of ground tracks. However, in order to apply data from different missions a dedicated pre-processing is necessary. The altimeter data were homogenized by applying the best known mission specific corrections. For the computation of altimetric sea surface heights, the standard corrections provided with the used altimeter products were applied with the modifications listed in Appendix A. Moreover, common geophysical models have been used for correcting ocean tides and the reaction of sea level to atmospheric pressure. Subsequently relative radial error components have been estimated by means of a multi-mission crossover analysis (Dettmering and Bosch, 2010). After correcting these radial errors, the altimeter data of all missions can be expected to be as consistent as possible.

The differences in Eq. (1) are then performed using the sea surface heights observed on the altimeter ground tracks. This method further on called profile approach has several
Table 1. The altimetric mission, data source and repeat cycle of each mission used for computing DOT.

\begin{tabular}{lrrl}
\hline Mission & Cycles & $\begin{array}{r}\text { Repeat period } \\
\text { (day) }\end{array}$ & $\begin{array}{l}\text { data } \\
\text { source }\end{array}$ \\
\hline Jason1 & $70-113$ & 10 & GDR-C CNES/NASA \\
T/P & $413-456$ & 10 & MGDR-B / NASA \\
ENVISAT & $23-34$ & 35 & GDR / CERSAT \\
GFO & $120-145$ & 17 & GDR / NOAA \\
\hline
\end{tabular}

advantages. First, it avoids any initial gridding which always implies an undesirable smoothing that is difficult to control. Second, the original sea surface heights observed along the ground tracks can be used with their high sampling rate. Finally, the method treats individual profiles and consequently results in estimates of instantaneous DOT profiles. It is then straightforward to use these DOT profiles in order to generate any temporal mean representing the DOT for a specific period of time. In this paper, instantaneous multi-mission DOT profiles are used to generate a time series of ten day DOT snapshots.

The difficulty in the profile approach is to ensure the consistent filtering of $h$ and $N$. Let 2-D[] be a two-dimensional filter operator, determined by the spectral properties of the geoid. A Gauss-type Jekeli-Wahr filter (Jekeli, 1981; Wahr et al., 1998) is used here as this filter has neither side lobes in the spectral domain nor in the spatial domain. Instead of Eq. (1), the DOT should be derived by applying the 2-D filter

$\mathrm{DOT}=2-\mathrm{D}\left[h-N^{\mathrm{SAT}}\right]=2-\mathrm{D}[h]-2-\mathrm{D}\left[N^{\mathrm{SAT}}\right]$,

where $N^{\mathrm{SAT}}$ denotes the geoid heights from the satellite only gravity field. As $h$ is not a two dimensional quantity, but available only along track profiles, only a one-dimensional filtering 1-D $[h]$ can be applied. In order to account for the systematic differences between one- and two-dimensional filtering, the identity

$$
\begin{aligned}
2-\mathrm{D}[h] & =1-\mathrm{D}[h]+2-\mathrm{D}[h]-1-\mathrm{D}[h] \\
& \approx 1-\mathrm{D}[h]+2-\mathrm{D}\left[N^{\mathrm{HR}}\right]-1-\mathrm{D}\left[N^{\mathrm{HR}}\right],
\end{aligned}
$$

is used and approximated by applying the last two filter operations to an ultra-high resolution geoid, denoted by $N^{\mathrm{HR}}$, derived from the EGM2008 (Pavlis et al., 2008), expanded in spherical harmonics up to degree and order 2190. Combining Eqs. (2) and (3) and re-ordering the filter operations give

$\mathrm{DOT}=1-\mathrm{D}\left[h-N^{\mathrm{HR}}\right]+\delta^{\mathrm{PG}}$,

where $\delta^{\mathrm{PG}}=2-\mathrm{D}\left[N^{\mathrm{HR}}\right]-2-\mathrm{D}\left[N^{\mathrm{SAT}}\right]=2-\mathrm{D}\left[N^{\mathrm{HR}}-N^{\mathrm{SAT}}\right]$ is the pre-geoid correction which can be computed in advance. Equation (4) shows that the instantaneous DOT profiles can be estimated by a one-dimensional filter operation applied to the difference between sea surface height and geoid height 


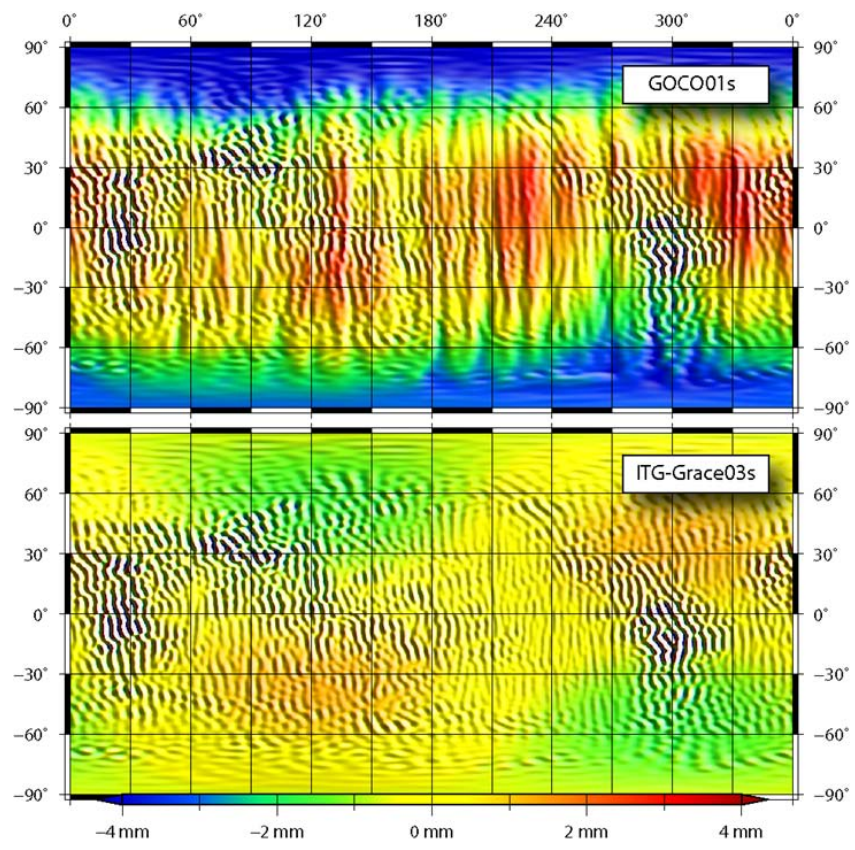

Fig. 1. Pre-Geoid corrections for GOCO01s and ITG-Grace03s gravity fields for Jekeli-Wahr filter with half width of $241.7 \mathrm{~km}$.

from EGM2008 performed for the along track sequence of observation points, plus the correction $\delta^{\mathrm{PG}}$ evaluated at the same points. Equation (4) seems to contradict the principle discussed below Eq. (1): to subtract geoid heights of satellite only models. EGM2008, used to compute $N^{\mathrm{HR}}$ in Eq. (4), is a hybrid model, based on marine gravity that in turn was derived from altimetry. Note, however, $N^{\mathrm{HR}}$ was introduced in Eq. (3) in order to compensate the systematic differences between one- and two-dimensional filtering. By re-ordering the apparently wrong geoid in Eq. (4) is compensated by the pre-geoid correction that represents the filtered difference between satellite-only and high-resolution geoid.

The magnitude of the pre-geoid correction is small and remains below a few millimetres. This is illustrated by the two panels of Fig. 1 showing for a filter length of $241 \mathrm{~km}$ the geographical pattern of $\delta^{\mathrm{PG}}$ computed for ITG-Grace03S (lower panel) and GOCO01S (upper panel). For ITG-Grace03S the $\delta^{\mathrm{PG}}$ values are even smaller than for GOCO01S. This is due to the fact that ITG-Grace $03 \mathrm{~S}$ has been used to construct the low degree part of EGM2008 (Pavlis et al., 2008). The $\delta^{\mathrm{PG}}$ values for GOCO01S exhibit some systematic differences. As GOCO01S is expected to provide a much better spatial resolution, filter operations with smaller filter length of 121 and $97 \mathrm{~km}$ were applied to GOCO01S only. As can be seen in Fig. 2, the magnitude of $\delta^{\mathrm{PG}}$ is inversely proportional to the filter length. The shorter the low-pass filter is the more details of high resolution geoid are passing the filter operation.

The results of the profile approach described thus far are instantaneous DOT profiles. The sequence of ten day DOTs

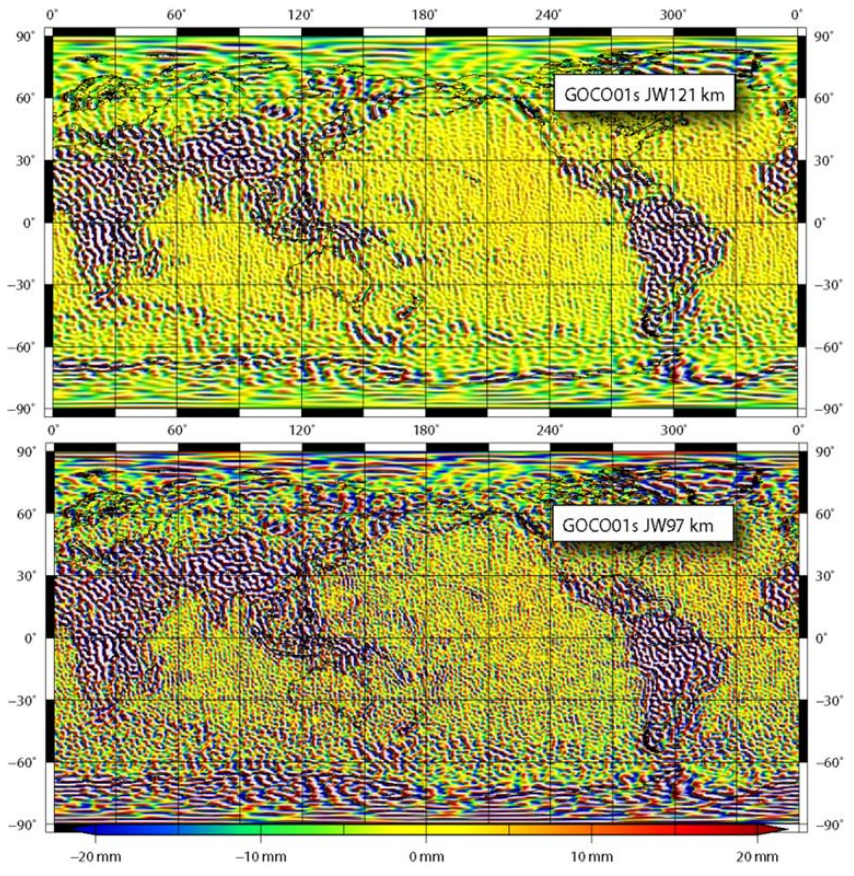

Fig. 2. Pre-Geoid corrections for GOCO01s gravity field and JekeliWahr filter with half width of 121 and $97 \mathrm{~km}$.

used for the assimilation are generated by linear interpolation onto the finite element mesh of the ocean model. This is done using distance dependent weighted mean of values from profiles lying in the cell near grid nodes. Figure 3 shows the snapshot of the multi-mission DOT computed for ten days using the filter length of $121 \mathrm{~km}$. All measurements lying within a ten day period were used. Therefore, the exact time in which measurements were made was not taken into account. Figure 3 shows the lack of data (white region) in the Southern Ocean where the ice covered area drifts zonally with the seasonal cycle so that the significant part of the surface appears to be ice-covered at least for some time during the year. In addition, radar altimetry suffers from systematic errors in estimating the sea state bias, an effect causing elongated radar distances in the presence of waves (Stammer et al., 2007; Chelton and Coauthors, 2001). This is particularly critical for the Southern Oceans with rather strong winds and large waves. The Weddell Sea is without any data coverage. Further data gaps that are seen in ten day estimates of DOT result from the interpolation of the altimetry profiles to the model grid, with an area of influence of $2^{\circ} \times 2^{\circ}$. This interpolation is kept as local as possible to avoid any additional filtering of the data. The described procedure produces for every 10 days maps of DOT. The mean over 10 day maps was calculated in order to investigate the information content of these data sets.

In Fig. 4, the mean over one year DOTs obtained using the profile approach is shown for the Jekeli-Wahr filter with half-width of $81 \mathrm{~km}$. The DOT itself exhibits the well-known 


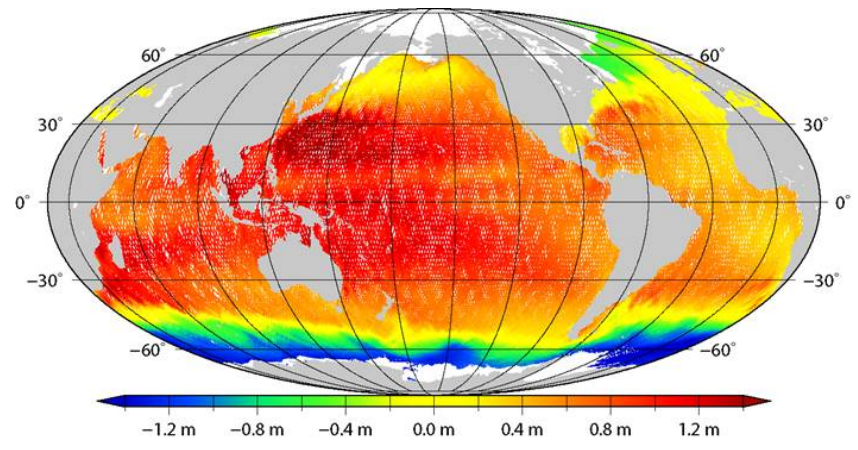

Fig. 3. DOT from TOPEX, Jason-1, GFO, and ENVISAT obtained from data within ten day interval around 25 April 2004 and geoid from GOCO1s model. The profile approach filtering was applied using Jekeli-Wahr filter with half width of $121 \mathrm{~km}$.

subpolar and mid latitude large scale gyres in both hemispheres. At this high resolution not only large scale but also smaller scales features of the circulation like the Labrador Current are visible. Pronounced patterns of the Antarctic Circumpolar Current (ACC) stand out. Separation and merging of fronts can be observed. The result of GOCO1s model filtered with a half width of $241 \mathrm{~km}$ was compared to the results using ITG-Grace03s. As can been seen in Fig. 5 where the difference between two mean fields is shown; these are almost identical. Small differences that do not exceed $0.5 \mathrm{~cm}$ can be still noted (see Fig. 5). In Fig. 5 also the differences between geodetic DOTs filtered using different filter lengths are plotted. Filtering with the smaller half widths allow many more details to remain in both altimetric and gravity field data. In particular, the main differences between the DOTs can be noted in the areas of strong currents, for example Gulf Stream, which now become much sharper. The differences are large if one compares results obtained by filtering with half widths of $241 \mathrm{~km}$ and $121 \mathrm{~km}$ (see Fig. 5 upper right) and to a lesser extent visible in the difference between $121 \mathrm{~km}$ and $97 \mathrm{~km}$ filtered results (lower left). The difference between the mean DOTs obtained as result of the filtering between $97 \mathrm{~km}$ (lower left) and $81 \mathrm{~km}$ on the other hand seems to be dominated by the noise. Further improvements are expected for these half widths once a full year of GOCE data are used instead of only two months which were available when this manuscript was prepared.

Therefore, the effect of filtering is to smear out the gradient resulting in weaker and less well defined estimates of the ocean currents. The filtered satellite data starting with half width of $121 \mathrm{~km}$ shows fine space scales that were previously poorly resolved with a width of $241 \mathrm{~km}$. However, also the time variability of the data sets are attenuated as a result of spatial filtering. Increase in resolution of the DOT accompanies the increase in the variability. In Fig. 6 increase in temporal variance is shown by the change of the filter length from $241 \mathrm{~km}$ to $121 \mathrm{~km}$ to $97 \mathrm{~km}$. The figure shows

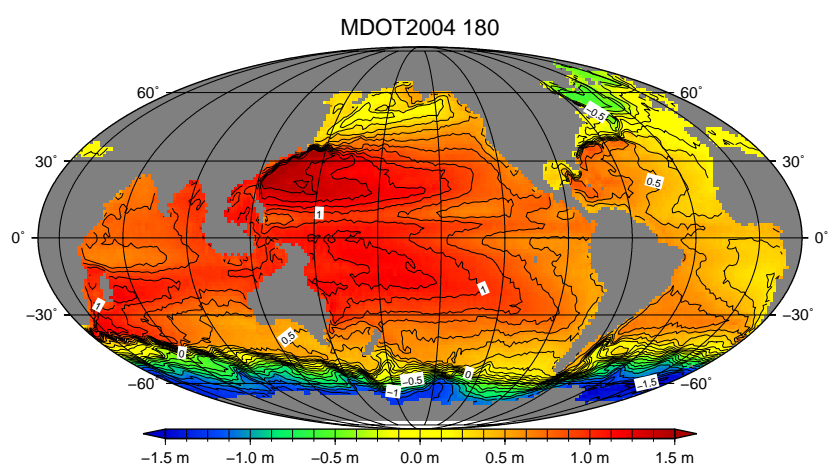

Fig. 4. Mean DOT obtained using geodetic approach with JekeliWahr filter with half width of $81 \mathrm{~km}$ and GOCO1s geoid that combines GRACE and GOCE gravity data.

the increase of the signal variance of sequences of ten day DOT grids by decrease of the filter lengths. The most significant changes occur in the change of the filter length from $241 \mathrm{~km}$ to $121 \mathrm{~km}$. The further reduction of the filter length leads to significant increase of the variances in the areas of significant variability of sea surface e.g. Gulf and Kuroshio streams. This is the result of smaller filter lengths resolving finer space scales. The apparent dilution of variance in polar and coastal areas can be explain by the better performance of the filter with the small filter length near the critical areas e.g. coast or sea ice boundaries.

\subsection{Argo data set}

For the validation of the results of the assimilation of DOT in Southern Atlantic, we use the Argo data set (http://www. argo.ucsd.edu, http://argo.jcommops.org). Since 1999, more than 200 Argo floats were deployed in the vicinity of the Weddell Gyre. These floats drift with the ocean currents at typically $800 \mathrm{~m}$ depth, collecting vertical profiles of temperature and salinity between $2000 \mathrm{~m}$ depth and the sea surface every 10 days. A quality control for temperature and salinity was applied according to Argo standards. The additional delayed mode quality control for salinity was performed as described in Owens and Wong (2009), i.e. comparing the float data with high quality reference CTD data (climatology). These comparisons are made on deep isotherms and assume that the temperature sensor of the float is stable and that salinity on deep isotherms is steady and uniform. The accuracy of the float data is better than $0.01{ }^{\circ} \mathrm{C}$ in temperature and 0.01 in salinity. The floats are modified with ice sensing algorithm, and have RAFOS tracking allowing them to operate during winter (Klatt et al., 2007).

A cycling period of 10 days allows using subsurface displacements as a direct and absolute measurement of the oceans' velocity at the parking depth $(800 \mathrm{~m}$ mostly). For the comparison in this study velocity components are calculated using the first Argos fix from the present cycle and 

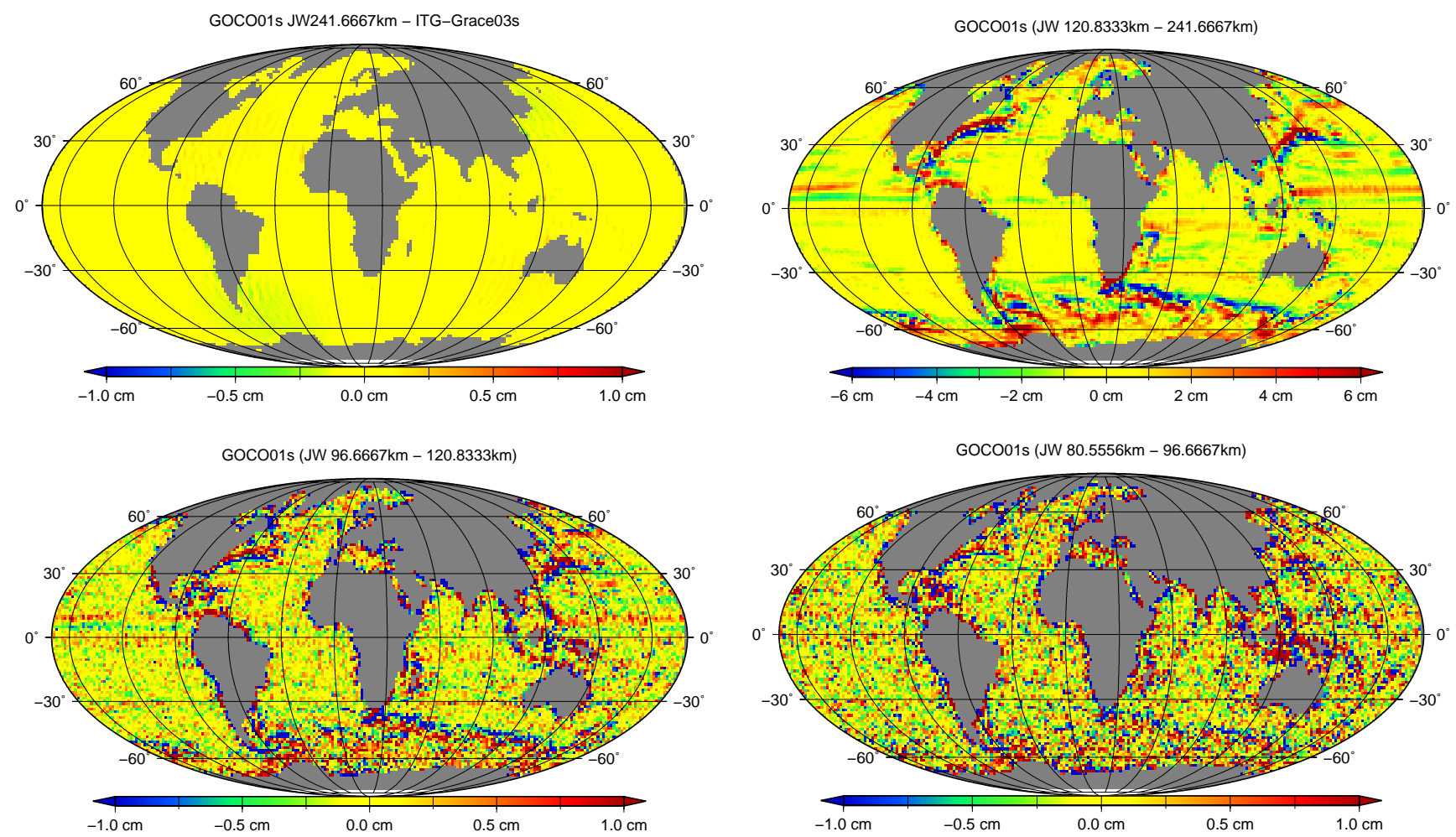

Fig. 5. The difference between mean geodetic DOTs obtained from GRACE data only and by combining GRACE and GOCE gravity data with both filtered using Jekeli-Wahr filter with half width of $241 \mathrm{~km}$ (upper left). The difference between geodetic DOTs obtained combining GRACE and GOCE gravity data filtered with half width of $241 \mathrm{~km}$ and $121 \mathrm{~km}$ (upper right), filtered with half width of $121 \mathrm{~km}$ and $97 \mathrm{~km}$ (lower left), filtered with half width of $97 \mathrm{~km}$ and $81 \mathrm{~km}$ (lower right). Note, color scale of the plots is different.
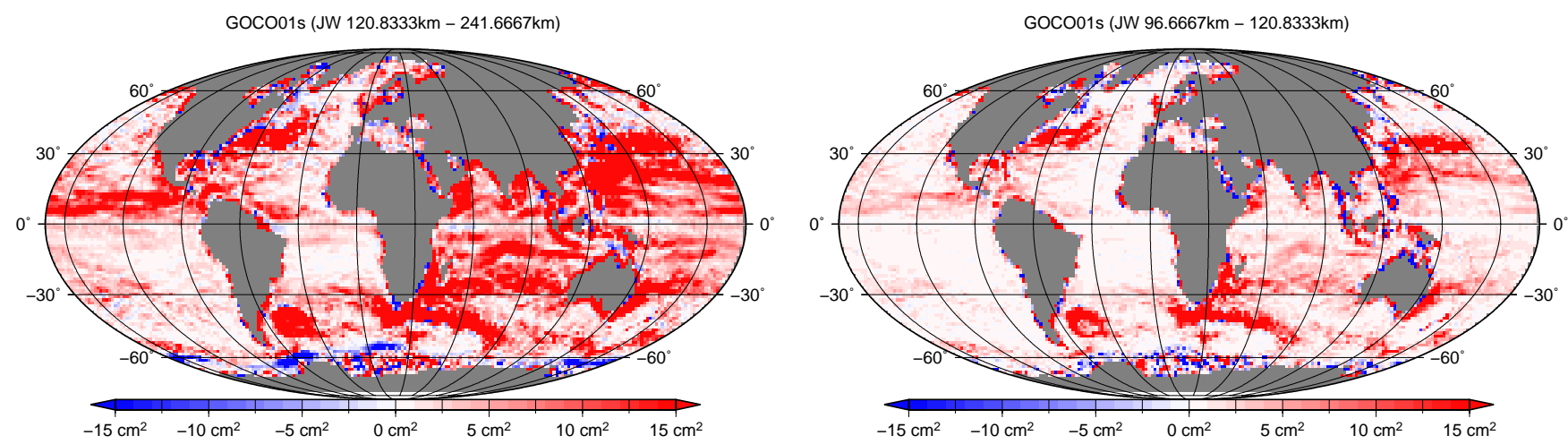

Fig. 6. Difference in temporal variance for 2004 between half width $241 \mathrm{~km}$ and $121 \mathrm{~km}$ filtering (left), between half width $121 \mathrm{~km}$ and $97 \mathrm{~km}$ (right).

the last Argos fix from the previous cycle and dividing each underwater displacement by its corresponding exact duration (Nunez-Riboni et al., 2005). The velocities were averaged into $1.5^{\circ}$ longitude by $1^{\circ}$ latitude bins. A simple low-pass filter (calculating the average of a bin and all of its eight immediate neighbors) was applied in each bin.

In Fig. 7, locations of the Argo floats used for this calculation are plotted. Differences in the regional coverage of the data that contribute to the composite can be noted. The Weddell gyre flow and in-situ temperature at $800 \mathrm{~m}$ are estimated from Argo data covering the period from 1999 to 2010. They are depicted in Fig. 13 for comparison with results of ocean modeling.

Besides the Argo composite that uses data from 1999 to 2010 to estimate the temperature and velocity field at $800 \mathrm{~m}$ (drifting depth), we will use also Argo profile data south of $40^{\circ} \mathrm{S}$ of potential temperature for year 2004 for additional validation. 


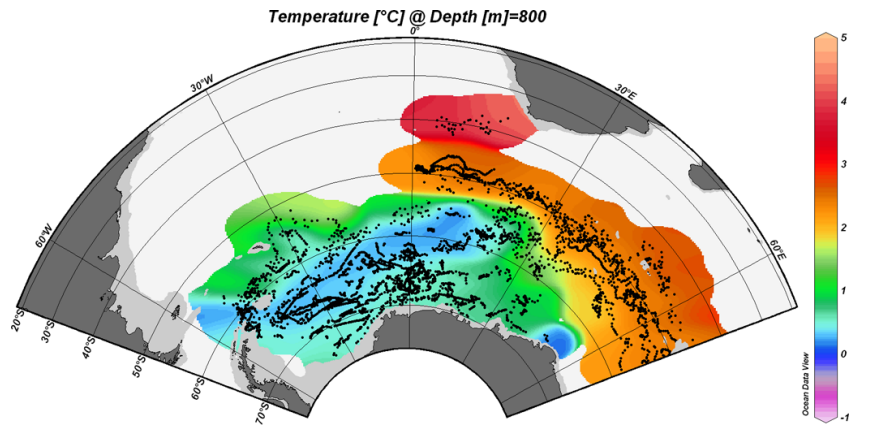

Fig. 7. Argo data locations used to make a composite.

\subsection{Satellite-tracked drifting buoys}

The Global Drifter Program of NOAA and AOML collects satellite-tracked drifting buoys ("drifter") measurements of upper ocean currents and sea surface temperature (SST). At www.aoml.noaa.gov/envids a large set of data from February 1979 to December 2010, covering almost all the sea surface, are available (Lumpkin and Garraffo, 2005). In this study, as second independent data set for validation, sea surface temperature measured by drifting buoys is used. The SST data is for the area of Drake Passage, $70^{\circ} \mathrm{S}$ to $40^{\circ} \mathrm{S}$ and $70^{\circ} \mathrm{W}$ to $20^{\circ} \mathrm{W}$, and for the time period from 1992 to 2010.

\section{Assimilation of DOT data}

\subsection{Data assimilation experiments}

The details of the data assimilation algorithm for the geodetic DOT obtained using GRACE data and altimetric measurements are described in Janjić et al. (2011a,b). In this section, we focus on modifications to the algorithm that need to be done in order to take into account higher resolution data. Further, we describe the assimilation scheme depending on the data and compare differences in the results of assimilation.

Four experiments were performed for the period between January 2004 and December 2004. These experiments were free model run, i.e. a model integration within the chosen time period without data assimilation and three experiments with assimilation of data filtered using Jekeli-Wahr filter with half widths of $241 \mathrm{~km}, 121 \mathrm{~km}$ and $97 \mathrm{~km}$. These experiments will be labeled A241, A121 and A97 respectively. For assimilation experiments, time varying DOT data are assimilated every 10 days. The data assimilation scheme corrects all the ocean fields, although only geodetic DOT is assimilated. A diagonal observation error covariance matrix is used with $5 \mathrm{~cm}$ STD for experiment A241 and A121 and $7 \mathrm{~cm}$ STD for experiment A97. The error variance includes the errors of altimetry and geoid data and mapping errors as well as the effects of cross-correlations introduced by the interpolation (Janjić and Cohn, 2006).
We use the domain localized singular evolutive interpolated Kalman filter (SEIK) algorithm (Pham et al., 1998; Pham, 2001; Nerger et al., 2006) as implemented within the parallel data assimilation framework (PDAF, Nerger et al., 2005). We update the full model state, consisting of temperature, salinity, SSH, and velocity fields. The SEIK algorithm is used together with the method of weighting observations proposed by Hunt et al. (2007). During the assimilation, the analysis of the full ocean state is carried out for each column of the model separately. The update of each column is assumed to depend only on observations within a specified influence region. In addition, the observations are weighted as a function of their distance from the point at which the assimilation is made. After obtaining the analysis the new ensemble is generated by second order exact resampling (Pham, 2001). Each ensemble is propagated with FEOM ocean model for 10 days producing the forecast of ensembles. Forecast of all model variables is obtained by averaging over the ensemble members. This forecasted field together with the next 10 day DOT map is used for obtaining the new analysis.

In Janjić et al. (2011a) it was shown that (a) the optimal influence region is a circle with a radius of $900 \mathrm{~km}$ for observations that are filtered with half width of $241 \mathrm{~km}$ and (b) that optimal covariance for localization of ensemble Kalman filter algorithm approximates well a Gaussian with length scale of $246 \mathrm{~km}$. For the data filtered up to $121 \mathrm{~km}$, experiments were performed using the same specification, as well as a localization function with length scale of $123 \mathrm{~km}$. For these two experiments, Fig. 8 shows the 10 day time evolution of the RMS error of the SSH for analysis and forecast compared to the data assimilated over the entire ocean. Further experiments with different length scale of localization function confirmed that the length scale of $123 \mathrm{~km}$ is optimal for observations that are filtered with half width of $121 \mathrm{~km}$. As seen in Fig. 8 the analysis results are closer to data than prediction. However the prediction drifts away from the analysis only moderately. The RMS error of the inferred DOT could be reduced from $16 \mathrm{~cm}$ (for the model only experiment compared to the geodetic DOT) to $4 \mathrm{~cm}$ for analysis and $5 \mathrm{~cm}$ for the prediction if proper length scale, depending on the data that is assimilated, is used. Accordingly, the length scale of localization function was chosen to have $98.4 \mathrm{~km}$ in experiment A97.

In order to start the sequential assimilation scheme described above the initial state and initial covariance need to be generated. The initial field and initial error covariance matrix used were the same as in Skachko et al. (2008). These were used to generate the initial ensemble of 13 model states by second-order exact sampling (Pham, 2001). 13 ensemble members were used for all the experiments. 

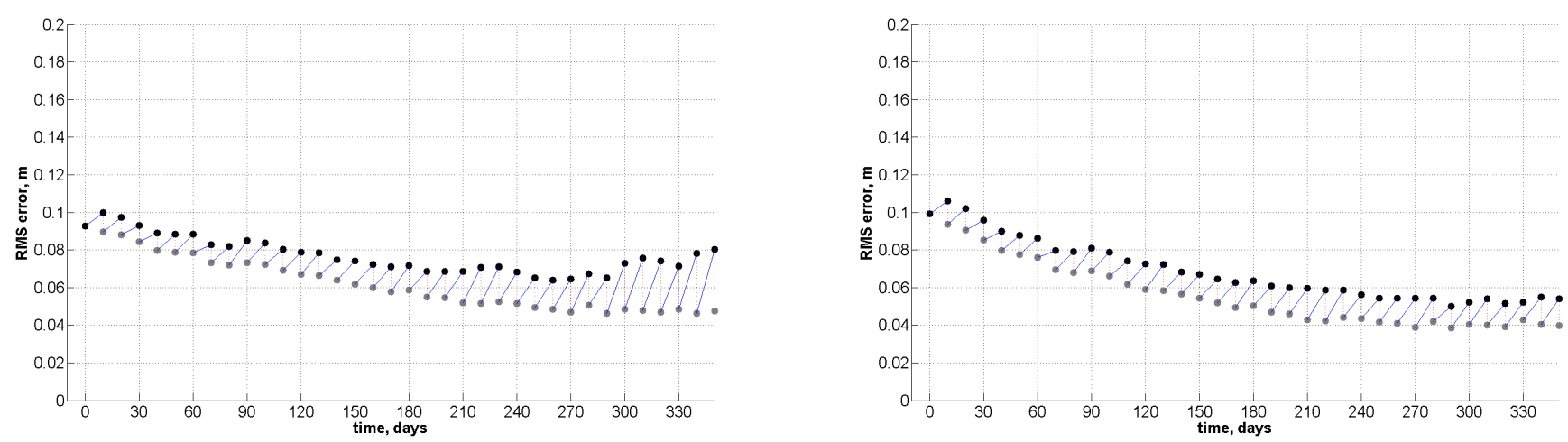

Fig. 8. Evolution of RMS error of SSH for the world ocean. The black bullets represent the sequence of 10-day model forecasts, while gray bullets correspond to the analysis. RMS error for assimilation of data filtered up to half width of $121 \mathrm{~km}$ and localization function that correspond to Gaussian with length scale $246 \mathrm{~km}$ (left). RMS error for assimilation of the same data with localization function that corresponds to Gaussian with length scale $123 \mathrm{~km}$ (right).
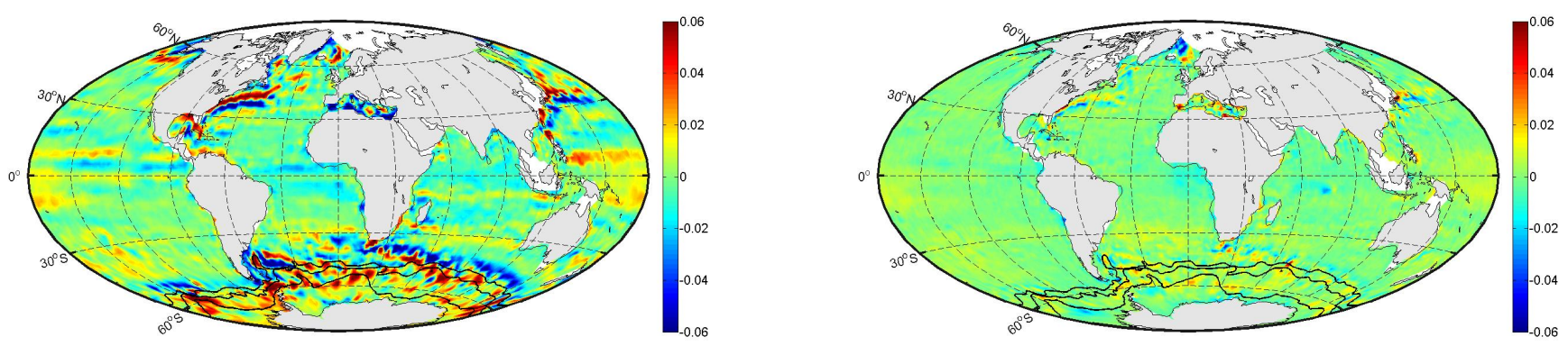

Fig. 9. The impact of increasing the resolution in the DOT data. Depicted is the difference between mean oceanic DOTs as a result of A241 and A121 experiments (left). The same for A121 and A97 experiments (right). Frontal positions of Orsi et al. (1995) are depicted with black lines. Units are $\mathrm{m}$.

\subsection{Results of global assimilation of DOT}

The DOT resulting from the data assimilation experiments reflects the impacts of the geodetic DOT data used, of the forcing, and of the physical and dynamical properties of the ocean model. In order to investigate the ability of the data assimilation scheme to incorporate the higher resolution data into the model, the difference between the mean analysis obtained as a result of assimilation of different resolution of data is considered. Figure 9 shows the difference between mean oceanic DOTs of A241 and A121 experiments as well as the difference for A121 and A97 experiments. We notice similar patterns and magnitudes as already shown in Fig. 5 for data only fields. The increase in resolution of data from the half width of 241 to $121 \mathrm{~km}$ modifies the DOT fields with the differences that can exceed $10 \mathrm{~cm}$, while the changes from the half width of 121 to $97 \mathrm{~km}$ are smaller and on the order of few centimeters. Corresponding results for SST show differences that are in the range of $0.5^{\circ} \mathrm{C}$ between the analysis results. For SST the major effects can be seen in the Southern Ocean, equatorial, as well as in the western boundary currents regions. The increase in resolution in sea surface salinity results is less pronounced compared to DOT or SST. Salinity, though, in the most active areas of the global ocean is effected by increase of resolution of DOT data as the other fields.

Finally, the variability is larger for the data less filtered, and therefore it is also more difficult to be reproduced by the model. Although data assimilation increases the variability of free model depending on the resolution of the data assimilated, all experiments show variability below the variability presented for DOT data in Fig. 6.

\subsection{Results of global assimilation of DOT in Southern Ocean}

The mean DOT obtained by averaging 10 day outputs from the free model can be subtracted from a corresponding mean geodetic DOT. The differences extend over large areas and have a significant magnitude (Köhl et al., 2007; Stammer et al., 2007; Skachko et al., 2008; Griesel et al., 2010; Janjić et al., 2011b) and particularly are large in Southern Ocean. The maximum amplitudes in the open ocean are located in the Southern Ocean east of South America and in between 

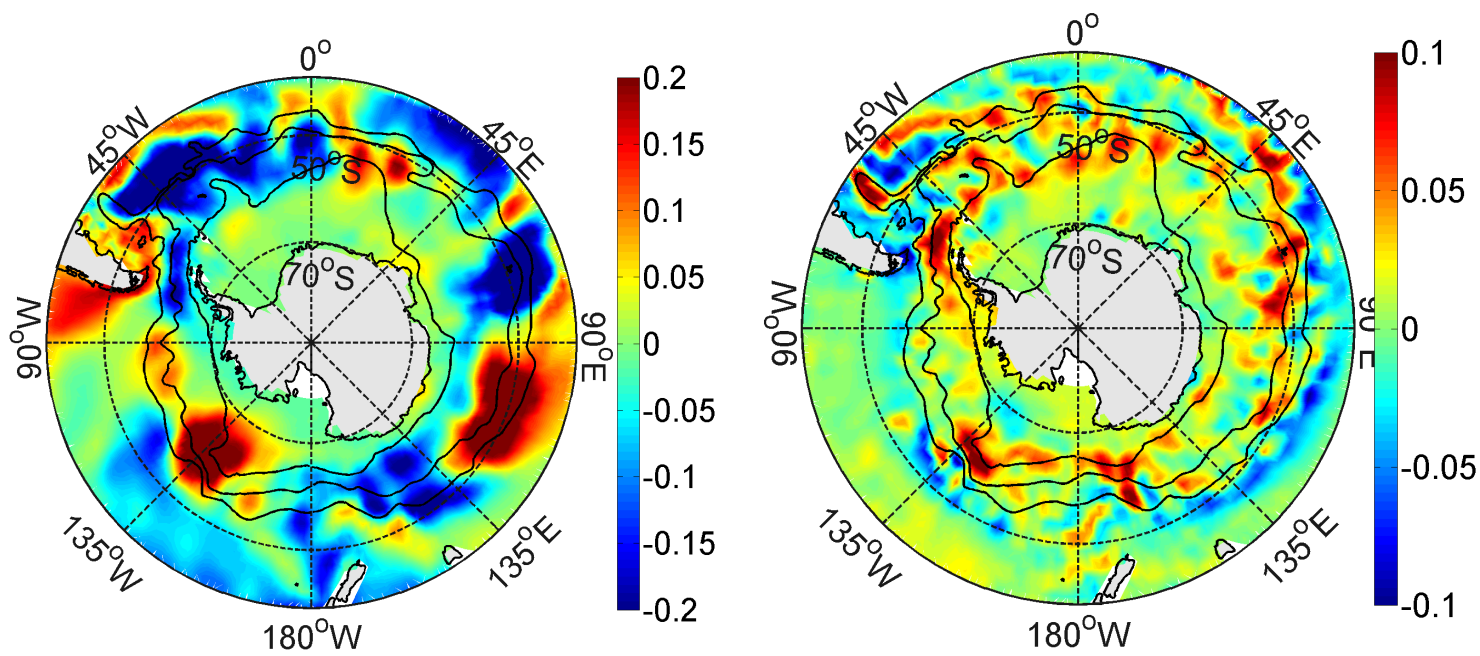

Fig. 10. The difference between mean analysis DOT of A241 and free model (left) and of A241 and A97 (right). The black lines are the Subantarctic, Polar and southern boundary of ACC fronts computed from in-situ measurements (Orsi et al., 1995). Units are m.
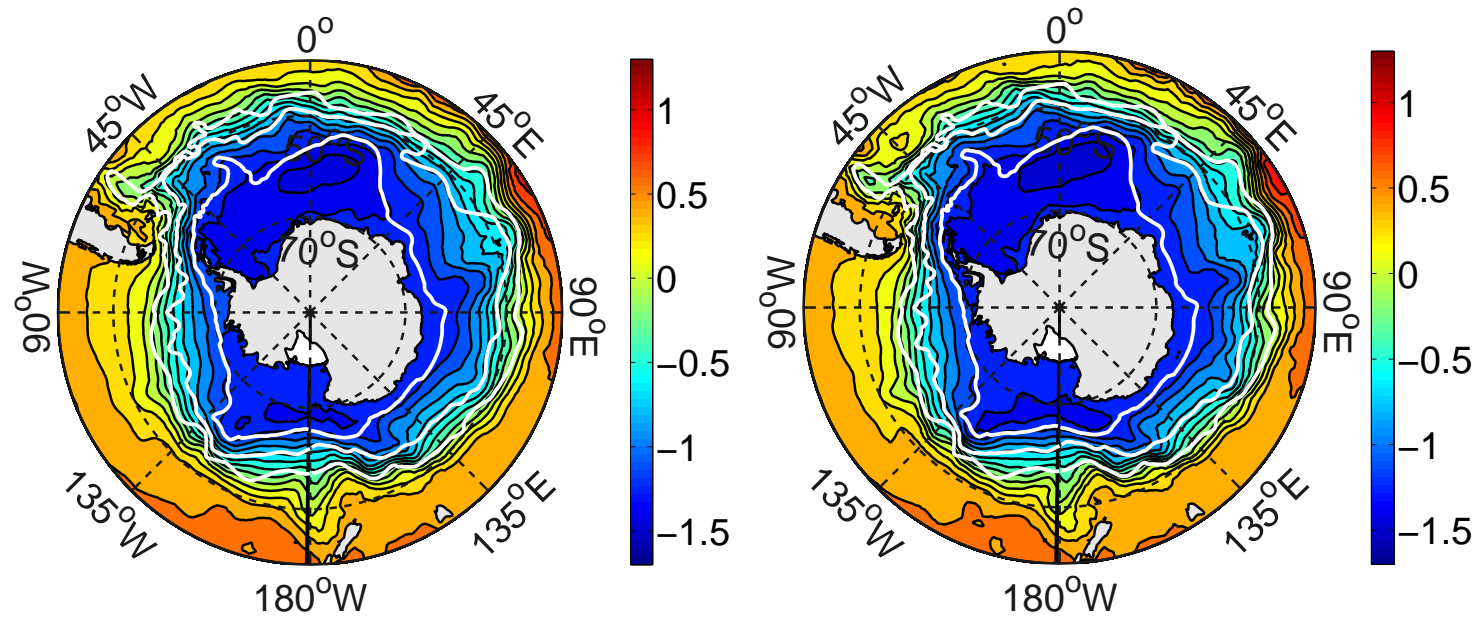

Fig. 11. The mean analysis DOT as result of A241 (left) and A97 (right) experiments for Southern Ocean. The white lines are the Subantarctic and Polar fronts and southern boundary of ACC computed from in-situ measurements (Orsi et al., 1995). Units are m.

$70^{\circ} \mathrm{E}$ and $120^{\circ} \mathrm{E}$, as well as at $140^{\circ} \mathrm{W}$. These locations are characterized by strong eddy activity. Higher resolution of GOCE data does not significantly decrease the differences. Its biggest impact is to sharpen the oceanic fronts.

Modification from the DOT of the free model to the DOT of A241 experiment is presented in Fig. 10 for Southern Ocean (left panel). Changes to the large scale flow field of a numerical model are significant, and as we will see later already the inclusion of the low resolution DOT improves the free model run. On the other hand, the difference between DOTs from experiments A241 and A97 are concentrated in the area of strong currents (right panel Fig. 10). Superimposed on the figures are location of the Subantartic and Polar fronts and southern boundary of ACC as estimated from historical hydrographic station data (Orsi et al., 1995).
Consistent with the increase in the resolution of the data, data assimilation results show that higher degree of DOTs further modify the areas of high variability. The mean DOT obtained as the result of analysis in the Southern Ocean for A241 and A97 experiment are shown in Fig. 11. Sokolov and Rintoul (2009) argue that the frontal location can be determined by the contour lines of SSH. In Fig. 11 the contour lines of SSH follow better the Orsi et al. (1995) front locations in Confluence Area of South Atlantic (East of the Argentine) where the turning of the Subantartic front now coincides with the estimates of location of this front by Orsi et al. (1995).

In order to verify the SST fields, the results of the four experiments are compared to SST from drifter measurements in the Drake Passage area. Eighteen years of drifter measurements as well as SST results of experiment A97 are 

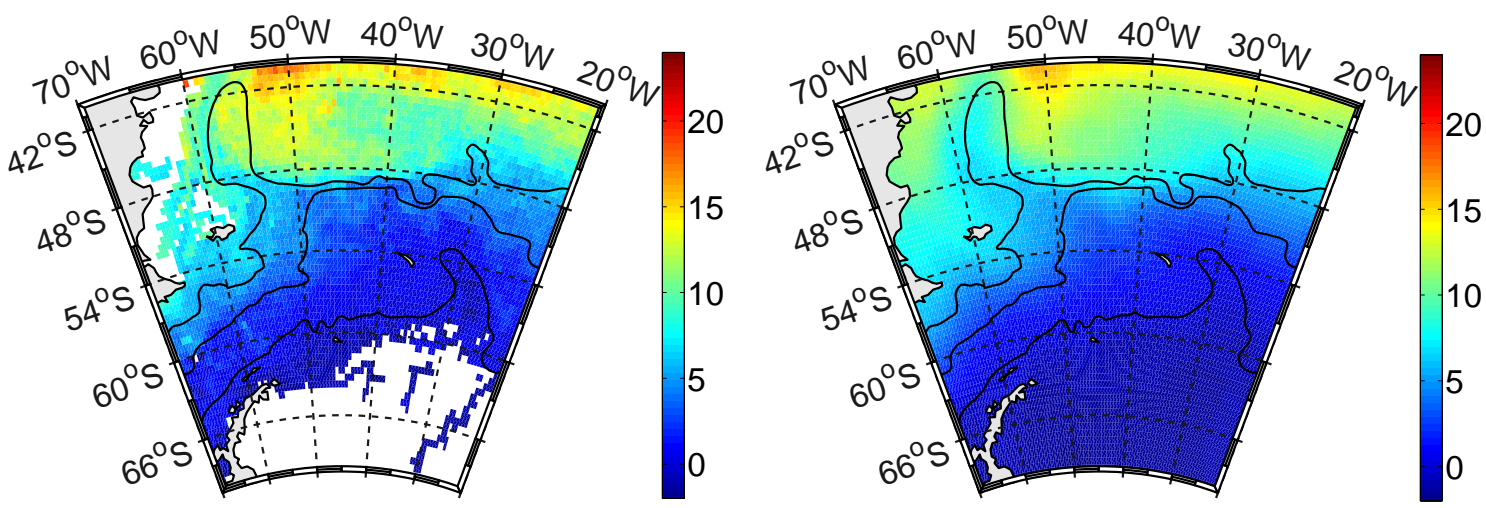

Fig. 12. The SST from surface drifter data in Drake passage area (left) and A97 experiment (right). The black lines are the Subantarctic and Polar fronts and southern boundary of ACC computed from in-situ measurements (Orsi et al., 1995). Units are Celsius.
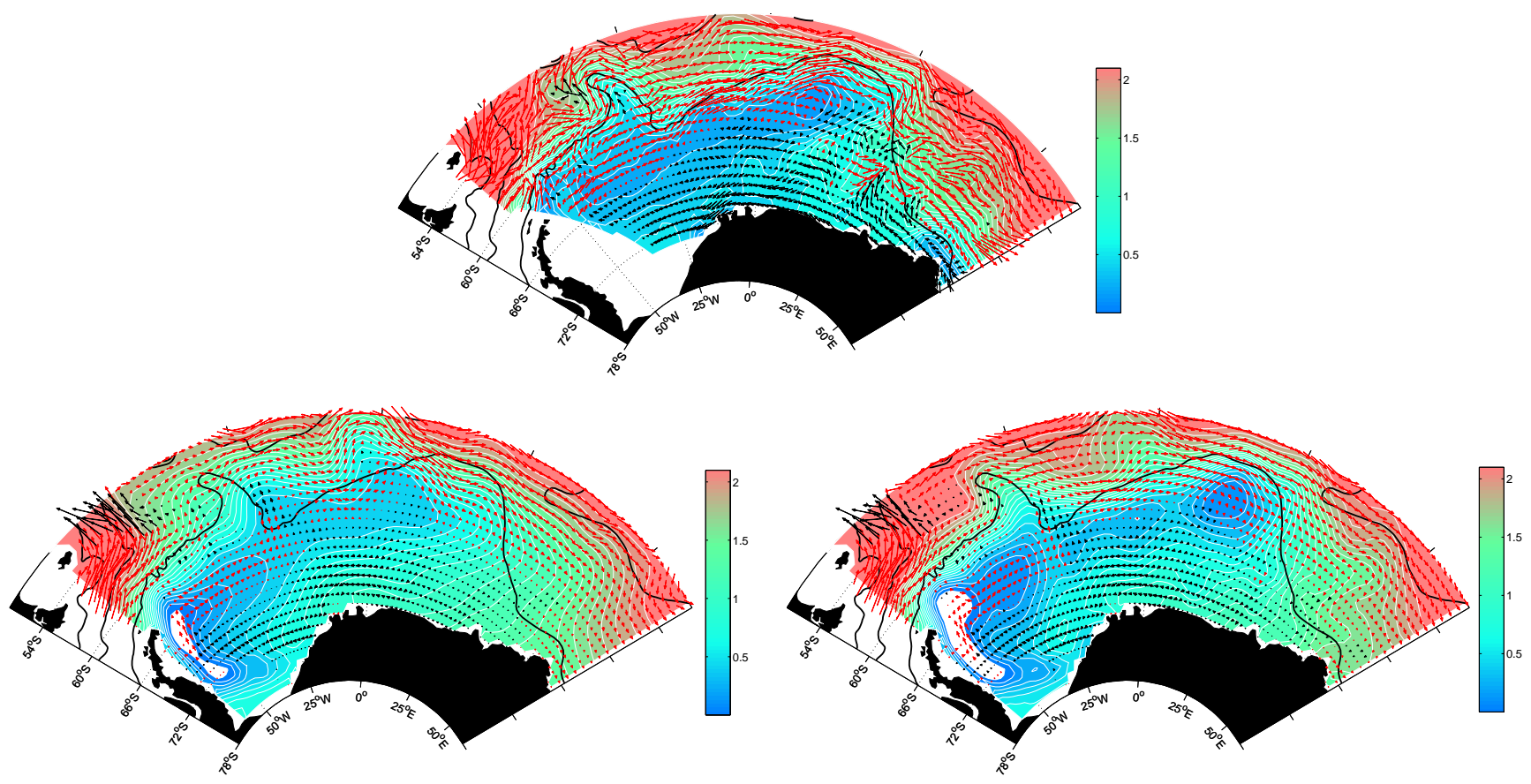

Fig. 13. The Weddell gyre flow and in-situ temperature at $800 \mathrm{~m}$ depth derived from 206 ice-compatible vertically profiling floats (Klatt et al., 2007) between 1999 and 2010 (top) following (Fahrbach et al., 2011). Corresponding figure for free model (bottom left) and A97 experiment (bottom right). Red and black arrows indicate eastward and westward currents, respectively. Frontal positions of Orsi et al. (1995) are depicted with black lines.

illustrated in Fig. 12. For the area with good drifter coverage, $60^{\circ} \mathrm{S}$ to $42^{\circ} \mathrm{S}$ and $58^{\circ} \mathrm{W}$ to $30^{\circ} \mathrm{W}$, the RMS error to SST drifter data was almost half once DOT data are assimilated. The errors as well as percentage of the erroneous signal are given in Table 2 for all four experiments. The improvement with different data resolution for SST is only $0.1^{\circ} \mathrm{C}$, from A241 to A97 experiments. Both model SST results as well as drifter data can be filtered in order to produce the comparable signal. This has been done using the spatial Gauss filter corresponding to the resolution of the DOT data, i.e. with half widths of 241, 121 and $97 \mathrm{~km}$. The RMS errors between the corresponding filtered fields were compared in Table 2. This comparison indicates a good reduction in the difference to drifter data for the large scale flow from $1.3^{\circ} \mathrm{C}$ to $0.6^{\circ} \mathrm{C}$ for $\mathrm{A} 241$ and $0.5^{\circ} \mathrm{C}$ for A97. The improvement compared to the free model run are for all scales. Since the $91 \%$ of drifter signal is explained by data filtered with half widths of $241 \mathrm{~km}$, the higher resolution of DOT data does not significantly effect the accuracy of the higher resolution SST data compared to drifter measurements. 

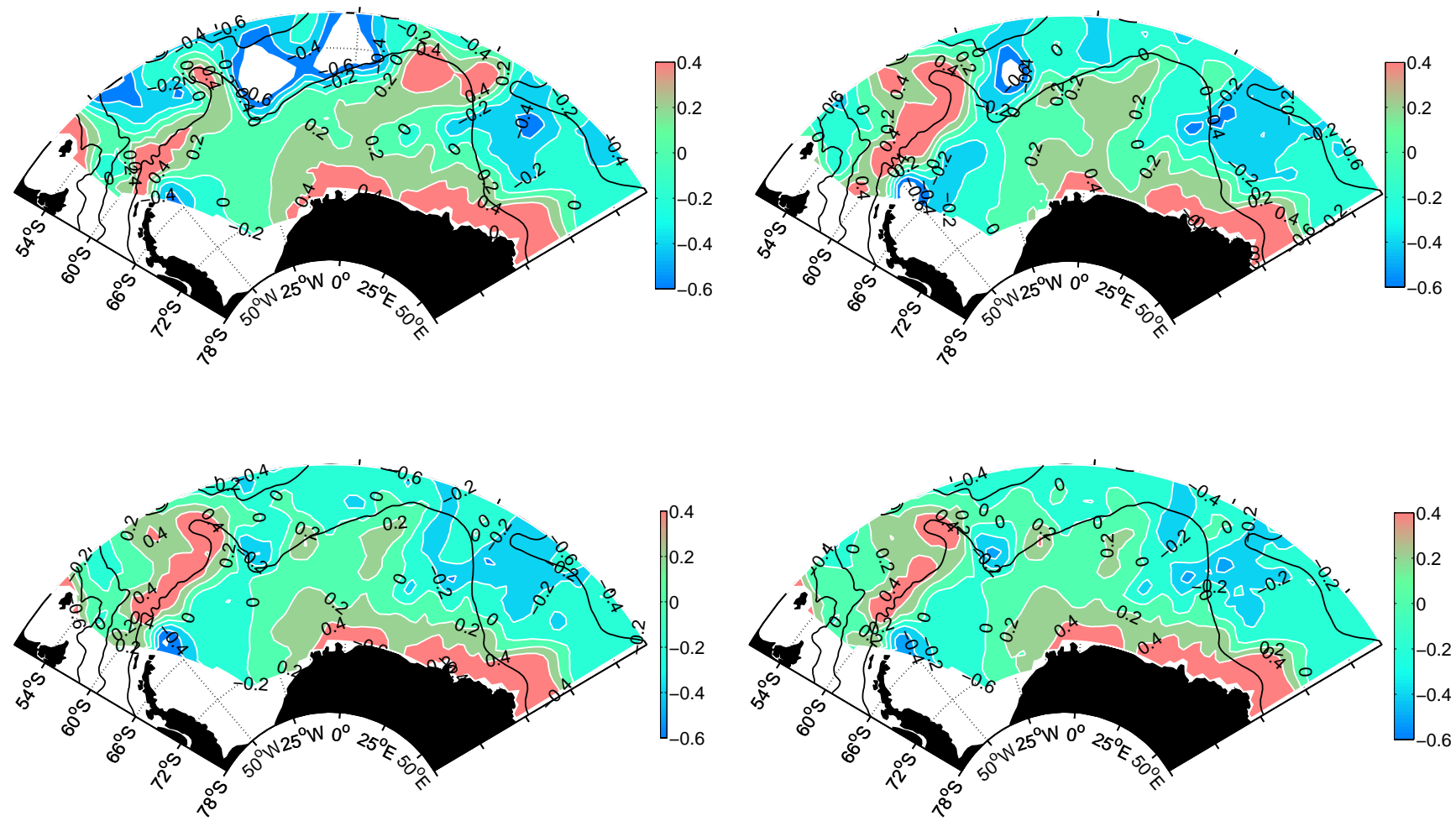

Fig. 14. The difference between in-situ temperature at $800 \mathrm{~m}$ depth from free model (upper left), A241 (upper right), A121 (lower left) and A97 (lower right) experiments and Argo composite, respectively. Frontal positions of Orsi et al. (1995) are depicted with black lines.

Table 2. SST RMS error values from four experiments compared to surface drifter data in Drake passage area. Units are degree Celsius. E241, E121 and E97 indicate the RMS error values when both SSTs are first filtered using Gauss spatial filter with half width of 241,121 and $97 \mathrm{~km}$, respectively. In parenthesis percentage of error for this area is given. Percentage is calculated by normalizing with RMS value of the drifter SST data or appropriately filtered drifter data in case of E241, E121 and E97.

\begin{tabular}{lcccc}
\hline & Model & A241 & A121 & A97 \\
\hline Full error & $1.9(26 \%)$ & $1.2(16 \%)$ & $1.1(16 \%)$ & $1.1(16 \%)$ \\
E241 & $1.3(19 \%)$ & $0.6(8 \%)$ & $0.5(8 \%)$ & $0.5(8 \%)$ \\
E121 & $1.6(22 \%)$ & $0.8(11 \%)$ & $0.8(11 \%)$ & $0.8(11 \%)$ \\
E97 & $1.7(23 \%)$ & $0.9(12 \%)$ & $0.8(12 \%)$ & $0.8(12 \%)$ \\
\hline
\end{tabular}

It is interesting to compare the assimilation results for subsurface temperature in the area which is only partially observed by altimetry, namely Weddell Sea. For this comparison we use the independent Argo data set (presented in Sect. 3.2) to show the impact of assimilation of global DOT. At about $30^{\circ} \mathrm{E}$, both temperature and flow field obtained from Argo data (see top panel of Fig. 13) show clearly the southward spreading of waters influenced by the ACC, resulting in an intrusion of warm water masses with temperatures of about $1{ }^{\circ} \mathrm{C}$ into Antarctic waters. From about $60^{\circ} \mathrm{S}$ southward, these waters spread to the west as part of the southern branch of the Weddell Gyre. Their subsequent transformation into deep and bottom water feeds the global thermohaline circulation. Additional southward float displacements are just about visible to the east of Conrad Rise at about $50^{\circ} \mathrm{E}$. Possibly, warmer waters from the north are entrained here into the Weddell Gyre as well, which would be consistent with Park and Gambéroni (1995), who place the boundary of the Weddell Gyre as far east as $60^{\circ} \mathrm{E}$ near the Kerguelen Plateau. In conjunction with the recirculation of the southern branch of the Weddell Gyre in the vicinity of the Greenwich Meridian and the temperature minimum at $\left(58^{\circ} \mathrm{S}, 10^{\circ} \mathrm{E}\right)$, this observation supports the double cell structure of the Weddell Gyre as suggested by Beckmann et al. (1999). The Subantartic and Polar fronts and southern boundary of ACC as estimated from historical station data (Orsi et al., 1995) are superimposed on the Fig. 13. It is interesting to note very good agreement between southern boundary of ACC as estimated by Orsi et al. (1995) with in situ data available at that time and the new Argo composite results.

Model only results show generally warmer water than observed (Fig. 13) by Argo data. East of the prime meridian temperatures below $0.5^{\circ} \mathrm{C}$ are not obtained. The most striking difference between model only and assimilation results is a spatial structure of temperature at $800 \mathrm{~m}$ depth (Fig. 13). 
The spatial distribution, similar as presented in the Fig. 13 for the results of assimilation of $97 \mathrm{~km}$ DOT data, appears already with assimilation of data filtered to $241 \mathrm{~km}$. In Fig. 14 the difference in temperature at $800 \mathrm{~m}$ depth to Argo composite is plotted for four experiments. Differences between temperature and Argo composite decrease with increased resolution. The area in between southern boundary of ACC and Polar front is represented better with use of the data assimilation and with use of higher resolution data. Warmer water is entrained between the front lines as result of assimilation in the area between $30^{\circ} \mathrm{W}$ and $0^{\circ}$, for example. Similarly with higher resolution data, area $25^{\circ} \mathrm{E}$ to $50^{\circ} \mathrm{E}$ and north of $54^{\circ} \mathrm{S}$ shows better agreement to the Argo data. Minima at $58^{\circ} \mathrm{S}$ at $10^{\circ} \mathrm{E}$ in the Argo data is seen in the assimilation of global DOT results, however more to the East than observed. Temperature in the area between $25^{\circ} \mathrm{W}$ to $25^{\circ} \mathrm{E}$ is now significantly closer to that observed by Argo. Also, water masses characterized by lower than observed temperature west of $30^{\circ} \mathrm{W}$ are closer to observed values with higher resolution data. Unfortunately the changes to the velocity field are very modest at $800 \mathrm{~m}$ level. Also the temperature field south of $66^{\circ} \mathrm{S}$ still is warmer than observed by Argo data.

RMS values for free model and for the three assimilation experiments, compared to Argo composite at $800 \mathrm{~m}$ are calculated. Use of data assimilation decreased the RMS differences for temperature and slightly for velocities once the data filtered to half width of $241 \mathrm{~km}$ are used. Further improvements can be noted when data with higher spectral resolution is assimilated. The RMS differences for A97 experiment are $0.35^{\circ} \mathrm{C}$ for temperature and $3.4,2.4 \mathrm{~cm} \mathrm{~s}^{-1}$ for velocity, north of $60^{\circ} \mathrm{S}$ values are $0.22{ }^{\circ} \mathrm{C}, 4$ and $2.8 \mathrm{~cm} \mathrm{~s}^{-1}$. In Table 3 two areas are chosen corresponding to the coverage of the Argo data (Fig. 7): area $I$ is from $55^{\circ} \mathrm{S}$ to $50^{\circ} \mathrm{S}$ and in between $0^{\circ}$ to $60^{\circ} \mathrm{E}$, and area $I I$ south of $55^{\circ} \mathrm{S}$ and from $40^{\circ} \mathrm{W}$ to $30^{\circ} \mathrm{E}$. The area II is without DOT data coverage. Similarly as for SST the largest reduction in error at $800 \mathrm{~m}$ depth is from free model run to A241. Additional reduction of the error due to the higher resolution of DOT data is not as large. In area II the errors are still large after assimilation, but the decrease in the error follows the increase in resolution. The calculated RMS errors for the velocity fields at $800 \mathrm{~m}$ depth remain large for both areas considered.

So far comparison of the four experiments with independent data has been done for the mean fields. Finally, the comparison of the potential temperature for all depths and for all Argo profiles south of $40^{\circ} \mathrm{S}$ for December 2004 is done (figure not shown). A decrease in the mean error with increased resolution occurs. The decrease is from $-0.3,-0.22,-0.17$, to -0.09 for free model, A241, A121 and A97. The STD follows $1.1,0.8,0.6$ to 0.95 respectively. The increase in the STD from A121 to A97 experiment is consistent with increase in noise of the DOT data for experiment A97.
Table 3. Normalized RMS error values from four experiments compared to the Argo data for the areas $I$ and $I I$ at $800 \mathrm{~m}$ depth. RMS errors are normalized with RMS value of Argo measurements and given as percentage.

\begin{tabular}{lrrrr}
\hline & Model & A241 & A121 & A97 \\
\hline Temperature $(\operatorname{area} I)$ & $16 \%$ & $10 \%$ & $10 \%$ & $8 \%$ \\
\hline$u(\operatorname{area} I)$ & $47 \%$ & $48 \%$ & $48 \%$ & $47 \%$ \\
$v(\operatorname{area} I)$ & $115 \%$ & $99 \%$ & $95 \%$ & $95 \%$ \\
\hline Temperature $(\operatorname{area} I I)$ & $49 \%$ & $41 \%$ & $38 \%$ & $38 \%$ \\
\hline$u(\operatorname{area} I I)$ & $81 \%$ & $76 \%$ & $76 \%$ & $76 \%$ \\
$v(\operatorname{area} I I)$ & $102 \%$ & $100 \%$ & $99 \%$ & $98 \%$ \\
\hline
\end{tabular}

\section{Conclusions}

Geodetic DOT with much finer space scales, that were previously poorly resolved, is obtained by combining GRACE and GOCE gravity field data. The resolution of the sea surface height data is still higher than the resolution of the geoid, and requires filtering in order to obtain spectrally consistent fields. In our study we used the profile approach filtering to obtain 10 day maps of DOT. Spatial filtering, in addition to removing noise also attenuates the gradients of DOT. By including two months of GOCE data the profile approach filtering was able to remove the noise and preserve as far as possible the oceanographic content of the DOT. The mean obtained by averaging 10 day geodetic estimates of DOT shows fine space scale structures that are particularly visible in the areas of strong currents. Further improvement in geodetic data sets is expected once more months of GOCE data become available.

Such a global geodetic data set was assimilated in a finite element ocean model. We investigated the impact of assimilation of global DOT data with different resolution. Results of assimilation show similar increase in the resolution of DOT obtained as seen in the data. Further, by assimilating globally DOT data, the model results can be further improved. For example, comparing the SST with the independent drifter data showed that the error in the Drake Passage area decreases from $1.9^{\circ} \mathrm{C}$ to $1.1^{\circ} \mathrm{C}$. However, the fine resolution of DOT did not significantly correct the errors in the finer scales of SST for this area. Comparison of the results with independent Argo data set shows positive impact of assimilation not only for DOT fields, and close to the surface, but also in temperature field at $800 \mathrm{~m}$ depth. In particular once the DOT data is assimilated the spatial structure of temperature at $800 \mathrm{~m}$ depth is closer to the one observed by Argo data. Once the temperature and salinity data are assimilated in the model, further improvements in results are expected. By assimilating only absolute dynamical topography data using the ensemble Kalman filter, we were able to obtain the results that are much closer to observations which 
were not used for assimilation and lie outside the area covered by altimetry in the Southern Ocean.

\section{Appendix A}

\section{Mission specific corrections}

First homogenization of the altimeter data was performed. This means that as far as possible the best mission specific corrections were applied and common geophysical models for the mean ocean tide models, geoid heights, and reaction of sea level to atmospheric pressure were used. For the computation of altimetric sea surface heights, the standard corrections provided with the used altimeter products (see Table 1) were applied with the following modifications:

1. for GFO the ionospheric corrections were computed from GIM ionospheric model scaled with the IRI model (Iijima et al., 1999);

2. all corrections described in Schrama et al. (2000) were applied to the ERS-1/2 data sets;

3. the orbit data of ERS-1/2 was replaced by DEOS precise orbits (Scharroo and Visser, 1998);

4. the GDR ENVISAT orbits were replaced by ESA orbits of GDR-C standards;

5. for Jason1 the radiometer wet troposphere correction are replaced using replacement product provided by Jet Propulsion Laboratory (JPL) (S. Desai, personal communication, 2009);

6. for the sea state bias of TOPEX, the model of Chambers et al. (2003) was used;

7. the orbits of TOPEX and Jason-1 missions were replaced by Lemoine et al. (2010);

8. for Jason-1, TOPEX/Poseidon and ENVISAT, the dual frequency ionospheric corrections were smoothed by means of median filter with the filter length of $20 \mathrm{sec}$;

9. the TOPEX microwave radiometer are replaced using replacement product (S. Desai, personal communication, 2003);

10. for all missions the inhomogeneous inverted barometric corrections were replaced by dynamic atmospheric corrections which are produced by CLS Space Oceanography Division using the Mog2-D model from Legos and distributed by Aviso, with support from Cnes (http: //www.aviso.oceanobs.com/);

11. for all altimeter systems the ocean tide corrections were computed using the EOT10a (Mayer-Gürr et al., 2012) tide model;
The second step was the multi-mission-cross-calibration. The radial error component and relative mission specific biases were corrected by means of multi-mission-crossover analysis (Dettmering and Bosch, 2010).

Acknowledgements. This work has been funded under DFG Priority Research Programme SPP 1257 "Mass Transport and Mass Distribution in the Earth System".

Edited by: E. J. M. Delhez

\section{References}

Beckmann, A., Hellmer, H., and Timmermann, R.: A numerical model of the Weddell Sea, large-scale circulation and water mass distribution, J. Geophys. Res., 104, 23374-23391, 1999.

Bingham, R. J., Haines, K., and Hughes, C. W.: Calculating the Ocean's Mean Dynamic Topography from a Mean Sea Surface and a Geoid, J. Atmos. Ocean. Tech., 25, 1808-1822, 2008.

Chambers, D. P., Hayes, S. A., Ries, J. C., and Urban, T. J.: New TOPEX sea state bias models and their effect on global mean sea level, J. Geophys Res., 108, 3305, doi:10.1029/2003JC001839, 2003.

Chelton, D. B., Esbensen, S. K., Schlax, M. G., Thum, N., Freilich, M. H., Wentz, F. J., Gentemann, C. L., McPhaden, M. J., and Schopf, P. S.: Observations of coupling between surface wind stress and sea surface temperature in the eastern tropical Pacific, J. Climate, 14, 1479-1498, doi:http://dx.doi.org/10.1175/15200442(2001)014<1479:OOCBSW>2.0.CO;2, 2011.

Danilov, S., Kivman, G., and Schröter, J.: A finite-element ocean model: principles and evaluation, Ocean Model., 6, 125-150, 2004.

Dettmering, D. and Bosch, W.: Global Calibration of Jason-2 by Multi-Mission Crossover Analysis, Mar. Geodesy, 33, 150-161, doi:10.1080/01490419.2010.487779, 2010.

Fahrbach, E.: Die Expedition ANTARKTIS XV/4 des Forschungsschiffes POLARSTERN 1998, [28. März 1998-23.'Mai 1998, Punta Arenas - Kapstadt $]=$ The expedition ANTARKTIS XV/4 of the research vessel POLARSTERN in 1998, Berichte zur Polar- und Meeresforschung = Reports on polar and marine research 314, Alfred Wegener Institute for Polar and Marine Research, 1999.

Fahrbach, E. and de Baar, H.: The expedition of the research vessel POLARSTERN to the Antarctic in 2008 (ANT-XXIV/3), Berichte zur Polar- und Meeresforschung $=$ Reports on polar and marine research 606, edited by: Fahrbach, E. and de Baar, H., Alfred Wegener Institute for Polar and Marine Research, 2010.

Fahrbach, E. and Naggar, S. E.: Die Expeditionen ANTARKTIS XVI/1-2 des Forschungsschiffes POLARSTERN 1998/1999= The expeditions ANTARKTIS XVI/1-2 of the research vessel POLARSTERN in 1998/1999, Berichte zur Polar- und Meeresforschung $=$ Reports on polar and marine research 380, Alfred Wegener Institute for Polar and Marine Research, 2001.

Fahrbach, E., Fuetterer, D. K., and Naggar, S. E. D. E.: Die Expedition ANTARKTIS XVIII/3-4 des Forschungsschiffes POLARSTERN 2000/2001 sowie die Aktivitaeten an Land und bei der Neumayer-Station $=$ The expedition ANTARKTIS XVIII/34 of the research vessel POLARSTERN in 2000/2001 including operations on land and at the Neumayer Station, Berichte zur 
Polar- und Meeresforschung $=$ Reports on polar and marine research 445, Alfred Wegener Institute for Polar and Marine Research, 2003.

Fahrbach, E., Hoppema, M., Rohardt, G., Boebel, O., Klatt, O., and Wisotzki, A.: Warming of deep and abyssal water masses along the Greenwich meridian on decadal time scales: The Weddell gyre as a heat buffer, Deep-Sea Res. Pt. II, 58, 2509-2523, doi10.1016/j.dsr2.2011.06.007, 2011.

Gouretski, V. V. and Koltermann, K. P.: WOCE Global Hydrographic Climatology, Bundesamt für Seeschifffahrt und Hydrographie, Hamburg und Rostock, Germany, 2004.

Griesel, A., Gille, S. T., and Mazloff, M.: Using dynamic ocean topography to probe the southern ocean circulation, Geophys. Res. Abstr., EGU2010-5565, EGU General Assembly 2010, Vienna, Austria, 2010.

Hunt, B. R., Kostelich, E. J., and Szunyogh, I.: Efficient Data Assimilation for Spatiotemporal Chaos: A local Ensemble Transform Kalman filter, Physica D, 230, 112-126, 2007.

Iijima, B. A., Harris, I. L., Ho, C. M., Lindqwister, U. J., Mannucci, A. J., Pi, X., Reyes, M. J., Sparks, L. C., and Wilson, B. D.: Automated daily process for global ionospheric total electron content maps and satellite ocean ionospheric calibration based on Global Positioning System, J. Atmos. Sol.-Terr. Phys., 61, 12051218, 1999.

Janjić, T. and Cohn, S. E.: Treatment of Observation Error due to Unresolved Scales in Atmospheric Data Assimilation, Mon. Weather Rev, 134, 2900-2915, 2006.

Janjić, T., Nerger, L., Albertella, A., Schroeter, J., and Skachko, S.: On domain localization in ensemble based Kalman filter algorithms, Mon. Weather Rev, 139, 2046-2060, doi:10.1175/2011MWR3552.1, 2011a.

Janjić, T., Schröter, J., Albertella, A., Bosch, W., Rummel, R., Savcenko, R., Schwabe, J., and Scheinert, M.: Assimilation of geodetic dynamic ocean topography using ensemble based Kalman filter, J. Geodynam., in press, doi:10.1016/j.jog.2011.07.001, 2011 b.

Jekeli, C.: Alternative methods to smooth the earth's gravity field, in: Dept. Geod. Sci. and Surv., Ohio State University, Columbus., rep. 327, 1981.

Klatt, O., Boebel, O., and Fahrbach, E.: A Profiling Float's Sense of Ice, J. Atmos. Ocean Tech., 24, 1301-1308, 2007.

Köhl, A., Stammer, D., and Cornuelle, B.: Interannual to Decadal Changes in the ECCO Global Synthesis, J. Phys. Oceanogr., 37, 313-337, 2007.

Le Grand, P., Schrama, E. J. O., and Tournadre, J.: An inverse estimate of the dynamic topography of the ocean, Geophys. Res. Lett., 30, 1062, doi:10.1029/2002GL014917, 2003.

Lemoine, F., Zelensky, N., D. S., Chinn, Pavlis, D., Rowlands, D., Beckley, B., Luthcke, S., Willis, P., Ziebart, M., Sibthorpe, A., Boy, J., and Luceri, V.: Towards development of a consistent orbit series for TOPEX/Poseidon, Jason-1, and Jason-2, Adv. Space Res., DORIS special issue, 46, 1513-1540, 2010.

Löhner, R., Morgan, K., Peraire, J., and Vahdati, M.: Finite-element flux-corrected transport (FEM-FCT) for the Euler and NavierStokes equations, Int. J. Numer. Meth. Fl., 7, 1093-1109, 1987.

Losch, M. and Schröter, J.: Estimating the circulation from hydrography and satellite altimetry in the Southern Ocean: limitations imposed by the current geoid models, Deep-Sea Res. Pt. I, 51, 1131-1143, 2004.
Lumpkin, R. and Garraffo, Z.: Evaluating the Decomposition of Tropical Atlantic Drifter Observations, J. Atmos. Ocean. Tech., 22, 1403-1415, 2005.

Maximenko, N., Niiler, P., Rio, M.-H., Melnichenko, O., Centurioni, L., Chambers, D., Zlotnicki, V., and Galperin, B.: Mean dynamic topography of the ocean derived from satellite and drifting buoy data using three different techniques, J. Atmos. Ocean. Tech., 26, 1910-1919., 2009.

Mayer-Gürr, T.: ITG-GRACE03s: The latest GRACE gravity field solution computed in Bonn, in: Presentation, Joint Grace Sc. Team and DFG SPP Meeting, Potsdam, Germany, Oct. 15, 2007, 2007.

Mayer-Gürr, T., Savcenko, R., Bosch, W., Daras, I., Flechtner, F., and Dahle, C.: Ocean tides from satellite altimetry and GRACE, J. Geodynam., in press, doi:10.1016/j.jog.2011.10.009, 2012.

Menkes, C., Boulanger, J., Busalacchi, A., Vialard, J., Delecluse, P., McPhaden, M., Hackert, E., and Grima, N.: Impact of TAO vs. ERS wind stresses onto simulations of the tropical Pacific Ocean during the 1993-1998 period by the OPA OGCM, in: Climate Impact of Scale Interaction for the Tropical Ocean-Atmosphere System, Vol. 13 of Euroclivar Workshop Report, 1998.

Nerger, L., Hiller, W., and Schröter, J.: PDAF - The Parallel Data Assimilation Framework: Experiences with Kalman filtering, in: Use of High Performance Computing in Meteorology, Proceedings of the 11. ECMWF Workshop, World Scientific, reading, UK, 25-29 October 2004, edited by: Zwieflhofer, W. and Mozdzynski, G., Singapore, 63-83, 2005.

Nerger, L., Danilov, S., Hiller, W., and Schröter, J.: Using sea level data to constrain a finite-element primitive-equation ocean model with a local SEIK filter, Ocean Dynam., 56, 634-649, 2006.

Nunez-Riboni, I., Boebel, O., Ollitrault, M., You, Y., Richardson, P., and Davis, R.: Lagrangian Circulation of Antarctic Intermediate Water in the subtropical South Atlantic, Deep-Sea Res. Pt. II, 52, 545-564, 2005.

Orsi, A. H., Whitworth III, T., and Nowlin Jr., W. D.: On the meridional extent and fronts of the Antarctic Circumpolar Current, Deep-Sea Res. Pt. I, 42, 641-673, 1995.

Owens, W. B. and Wong, A. P. S.: An improved calibration method for the drift of the conductivity sensor on autonomous CTD profiling floats by theta-S climatology, Deep-Sea Res. Pt. I, 56, 450457, 2009.

Pail, R., Goiginger, H., Schuh, W. D., Höck, E., Brockmann, J. M., Fecher, T., Gruber, T., Mayer-Gürr, T., Kusche, J., Jäggi, A., and Rieser, D.: Combined satellite gravity field model GOCO01S derived from GOCE and GRACE, Geophys. Res. Lett., 37, L20314, 5 pp, doi:10.1029/2010GL044906, 2010.

Pakanowski, R. and Philander, S.: Parametrization of vertical mixing in numerical models of tropical oceans, J. Phys. Oceanogr., 11, 1443-1451, 1981.

Park, Y.-H. and Gambéroni, L.: Large-scale circulation and its variability in the South Indian Ocean from TOPEX/POSEIDON altimetry, J. Geophys. Res., 100, 911-924, 1995.

Pavlis, N. K., Holmes, S. A., Kenyon, S. C., and Factor, J. K.: An Earth Gravitational Model to Degree 2160: EGM2008, Geophys. Res. Abstr., EGU2008-A-01891, EGU General Assembly 2008, Vienna, Austria, 2008.

Penduff, T., Brasseur, P., Testut, C.-E., Barnier, B., and Verron, J.: A four-year eddy-permitting assimilation of sea-surface temperature and altimetric data in the South Atlantic Ocean., J. Mar. 
Res., 60, 805-833, 2002.

Pham, D. T.: Stochastic methods for sequential data assimilation in strongly nonlinear systems, Mon. Weather Rev., 129, 11941207, 2001.

Pham, D. T., Verron, J., and Gourdeau, L.: Singular evolutive Kalman filters for data assimilation in oceanography, C. R. Acad. Sci. Ser. II, 326, 255-260, 1998.

Rio, M.-H., Schaeffer, P., Lemoine, J.-M., and Hernandez, F.: Estimation of the ocean Mean Dynamic Topography through the combination of altimetric data, in-situ measurements and GRACE geoid: From global to regional studies, Proceedings of the GOCINA international workshop, Luxembourg, 2005.

Rio, M.-H., Schaeffer, P., Moreaux, G., Lemoine, J.-M., and Bronner, E.: A new mean dynamic topography comuted over the global ocean from GRACE data, altimetry and in-situ measurements, in: OceanObs09 Venice, poster, 2009.

Rollenhagen, K., Timmermann, R., Janjić, T., Schroeter, J., and Danilov, S.: Assimilation of sea ice motion in a Finite Element Sea Ice Model, J. Geophys. Res., 114, C05007, doi:10.1029/2008JC005067, 2009.

Scharroo, R. and Visser, P. N. A. M.: Precise orbit determination and gravity field improvement for the ERS satellites, J. Geophys Res., 103, 8113-8127, 1998.

Schrama, E., Scharroo, R., and Naeije, M.: Radar Altimeter Database System (RADS): Towards a generic multi-satellite altimeter database system, USP-2 00, BCRS/SRON, Delft, The Netherlands, 2000.

Schröder, M. and Fahrbach, E.: On the structure and the transport in the Eastern Weddell Gyre, Deep-Sea Res. Pt. II, 46, 501-527, 1999.

Schröter, J., Losch, M., and Sloyan, B.: Impact of the Gravity Field and Steady-State Ocean Circulation Explorer (GOCE) mission on ocean circulation estimates 2, Volume and heat transports across hydrographic sections of unequally spaced stations, J. Geophys. Res., 107, 11-13, doi:10.1029/2000JC000647, 2002.
Sidorenko, D., Wang, Q., Danilov, S., and Schröter, J.: FESOM under Coordinated Ocean-ice Reference Experiment forcing, Ocean Dynam., 61, 881-890, doi:10.1007/s10236-011-0406-7, 2011.

Skachko, S., Danilov, S., Janjić, T., Schröter, J., Sidorenko, D., Savcenko, R., and Bosch, W.: Sequential assimilation of multimission dynamical topography into a global finite-element ocean model, Ocean Sci., 4, 307-318, doi:10.5194/os-4-307-2008, 2008.

Sokolov, S. and Rintoul, S. R.: Circumpolar structure and distribution of the Antartic Circumpolar Current Fronts: Mean circumpolar parts, J. Geophys. Res., 114, 1-19, 2009.

Stammer, D., Köhl, A., and Wunsch, C.: Impact of accurate Geoid fields on Estimates of the Ocean Circulation, J. Atmos. Ocean. Tech., 24, 1464-1478, 2007.

Stephens, J., Antonov, T., Boyer, T., Conkright, M. E., Locarnini, R. A., OBrien, T. D., and Garcia, H. E.: World ocean Atlas 2001, in: Temperatures, edited by: Levitus, S., NOAA Atlas NESDIS 49, US Government Printing Office, 167 pp., 2002.

Timmermann, R., Danilov, S., Schröter, J., Böning, C., Sidorenko, D., and Rollenhagen, K.: Ocean circulation and sea ice distribution in a finite element global sea ice-ocean model, Ocean Model., 27, 114-129, 2009.

Wahr, J., Bryan, F., and Molenaar, M.: Time variability of the Earth's gravity field: Hydrological and oceanic effects and their possible detection using GRACE, J. Geophys. Res., 103, 3020530229, 1998.

Wang, Q., Danilov, S., and Schroeter, J.: Finite element ocean circulation model based on triangular prismatic elements with application in studying the effect of topography representation, J. Geophys. Res., 113, C05015, 21 pp., doi:10.1029/2007JC004482, 2008.

Wenzel, M. and Schröter, J.: Assimilation of TOPEX/POSEIDON altimer data into a global primitive equation model, in: Minutes of the TOPEX/POSEIDON Science Working Team Meeting, C18-C23, JPL D12817, 176 pp., 1995. 